\title{
Debatedor
}

\section{A política do possível ou a política da utopia?}

The possible policy or the utopian policy?

Leticia Coelho da Costa Nobre ${ }^{1}$

Estou muito grata por participar deste debate que considero da maior relevância no atual contexto brasileiro de esforços coletivos para avançar nas políticas públicas e não retroceder nas conquistas sociais frente ao desenvolvimento econômico. Reflexões teóricas e conceituais desempenham importante papel na construção do campo da saúde do trabalhador no país. Os autores Costa, Lacaz, Jackson Filho e Vilela (2013) discorrem com muita propriedade sobre o quadro do mundo de trabalho contemporâneo, sobre o contexto do desenvolvimento e crescimento econômico no Brasil, com a predominância e a hegemonia dos interesses do capital em detrimento das políticas sociais, dentre elas a Política Nacional de Saúde do Trabalhador e da Trabalhadora (PNSTT) no âmbito do Sistema Único de Saúde.

${ }^{1}$ Vigilância e Atenção à Saúde do Trabalhador, Superintendência de Vigilância e Proteção à Saúde, Secretaria da Saúde do Estado da Bahia. Salvador, BA, Brasil. E-mail: leticia.nobre@saude.ba.gov.br. 
Questões importantíssimas foram explicitadas acerca da centralidade do trabalho na vida das pessoas e dos coletivos humanos; das relações sociais e políticas, de dominação, de práticas hegemônicas e contra-hegemônicas; dos valores e princípios que informam as políticas públicas e as práticas dos sujeitos; das contradições e dos paradoxos que vivemos nos ambientes de trabalho, nas instituições e serviços de Saúde, do Trabalho, da Previdência Social, entre outras. Do papel do Estado. Dos sujeitos da história. Minha contribuição a este debate parte de meu lugar enquanto um dos sujeitos na construção da política de saúde do trabalhador, compartilhada com tantos outros, seja na Bahia ou no Brasil.

Os autores propõem que a política de Estado, relativa aos setores Trabalho e Previdência, constituída na época da ditadura militar "prevalece até hoje sem grandes mudanças substantivas". Essa é uma questão importante sobre a qual necessitamos refletir. Vivenciamos o processo de redemocratização do país, os movimentos sociais e sindicais do final dos anos 1970 e anos 1980, a árdua construção da Constituição Federal de 1988, que propôs novas configurações e competências institucionais, dentre as quais a criação do Sistema Único de Saúde (SUS). De lá para cá, todos enfrentamos crises, dificuldades e desafios. Vivenciamos o subfinanciamento em vários setores, as ameaças de privatização do seguro acidente de trabalho. Muitas mudanças ocorreram, algumas em direção a avanços reais, trazendo o novo, outras nem tanto.

Que outros elementos podem auxiliar na avaliação dos nós críticos das relações interinstitucionais entre Saúde, Trabalho e Previdência Social? Estes são três sujeitos institucionais e áreas de políticas públicas da maior importância não só para os trabalhadores, mas para toda a sociedade brasileira. Suas relações ao longo desses anos precisam ser analisadas considerando-se as concepções sobre o papel do Estado e as políticas sociais, que se traduzem tanto em ações e intervenções do Estado em planos e dimensões macropolíticas, quanto em processos singulares de sujeitos sociais em cada ambiente, organização e instituição. Para avançar, é necessário explicitar as diferentes concepções, propósitos e metodologias, ao mesmo tempo buscar os objetivos comuns e incluir as expectativas de cada ator. Será que perdemos uma oportunidade histórica de mudar o quadro institucional - e a política brasileira para a ST - quando, em 1993 (IX Conferência Nacional de Saúde) e em 1994 (2ª Conferência Nacional de ST) (BRASIL, 1994), as conferências deliberaram pela integração no SUS dos setores de SST do Ministério do Trabalho e Emprego (MTE) e Fundacentro? Esse foi um momento histórico de ruptura e acirrado conflito interinstitucional. Ao mesmo tempo, outros processos e avanços ocorreram em cada instituição, alguns compartilhados, outros não.
Outro momento histórico crítico foi o da $3^{\mathrm{a}}$ Conferência Nacional de Saúde do Trabalhador (CNST), realizada em 2005. A despeito de ter sido convocada pelos três ministérios, com discussões articuladas em torno de eixos temáticos que permitiriam a técnicos, gestores e sociedade civil organizada refletir sobre o mundo do trabalho, seus impactos sobre a saúde e as relações interinstitucionais, ela aconteceu sob um clima de crise e resistência deliberada por parte de parcela dos auditores fiscais do trabalho (NOBRE, 2011). Vale ressaltar que durante esta conferência, a proposta de Política Nacional de Segurança e Saúde do Trabalhador (PNSST), que havia sido construída pelo Grupo Executivo Interministerial de Saúde do Trabalhador (Geisat) desde 2003, foi apresentada oficialmente pelos três ministros e colocada em consulta pública (BRASIL, 2005).

Apesar de apresentar ambiguidades em relação aos conceitos, conforme explícito no próprio nome proposto para a política, indefinição quanto às competências comuns e cooperadas entre os três ministérios, além de insuficiente explicitação das responsabilidades, necessidades de financiamento e dos mecanismos de participação e controle social, esta proposta foi avaliada como tendo apresentado um elenco razoável de possibilidades para a atuação dos três ministérios, expresso nas estratégias propostas para cada diretriz (NOBRE, 2011). Não foi a melhor, mas era a política possível para seu momento histórico. Tinha um propósito que ainda hoje se faz necessário: avançar na integração e na redução da fragmentação das políticas de interesse à Saúde do Trabalhador.

E hoje? Como entender a persistência de disputas, conflitos e discrepâncias, inclusive de valorização social do trabalho de cada um? É fato que o exercício da intersetorialidade, com raras exceções, continua sendo difícil. Então, cabe perguntar-nos: a quem mesmo interessa a persistência da fragmentação e dos conflitos institucionais? Como analisar as dificuldades, os nós críticos e os resultados também da Previdência Social e do MTE? Como avançar em relações solidárias e compartilhadas, com propósitos comuns de promoção e proteção da saúde dos trabalhadores?

Ainda há outros dois atores institucionais importantes a serem incluídos nesta relação: o Meio Ambiente e as secretarias do trabalho de estados e municípios. Em espaços, conselhos, órgãos setoriais e políticas ambientais, são definidos que empreendimentos e atividades produtivas serão implantados nos territórios. Nos estados e nos municípios, as secretarias do trabalho e emprego são potenciais aliados para a promoção de trabalho e empregos decentes, na construção de um sistema nacional de trabalho, emprego e geração de renda, na diminuição 
dos trabalhos precários e na inclusão de parcelas de trabalhadores tradicionalmente excluídos dessas políticas (BAHIA, 2011; ABRAMO, 2010). Por sua vez, o SUS tem grande potencial de contribuição para a promoção do trabalho decente mediante especialmente as ações de vigilância de ambientes e processos de trabalho, produção de informações sobre situação de saúde dos trabalhadores e participação em processos regulatórios (NOBRE, 2010).

As reflexões acerca dos modelos de regulação do estado e de participação e controle social das políticas públicas são bastante pertinentes. Assistimos ao longo da década de 1990 à morosidade, quando não o engavetamento, de diversas propostas inovadoras, como é o caso da Cipa totalmente eleita pelos trabalhadores. Por outro lado, à criação de comissões tripartites, funcionando somente mediante consensos, evitando que propostas contrárias aos interesses empresariais sejam arrastadas por décadas. Vejamos o exemplo ímpar do acordo e legislação sobre o benzeno, que até hoje sofre pressões empresariais em direção a seu retrocesso e somente resiste pelo compromisso e propósitos comuns compartilhados entre auditores fiscais do trabalho e técnicos do SUS, em aliança com os trabalhadores. Não tendo conseguido, até então, ampliar essa experiência para outros agentes químicos, finalmente, este ano, a Previdência Social assumiu a avaliação qualitativa da exposição a substâncias carcinogênicas nos processos de aposentadoria especial (BRASIL, 2013).

Precisamos questionar essa lógica de que sempre é melhor produzir consensos e rever a forma de funcionamento de alguns fóruns tripartites. Esperar pelo consenso frequentemente é a não tomada de posição do Estado perante uma situação de conflito em que a balança pesa para os interesses mais poderosos, que, em nosso caso, são quase sempre do capital. É a política da omissão. O caso da I ${ }^{\mathrm{a}}$ Conferência Nacional de Emprego e Trabalho Decente, realizada em agosto de 2012, e interrompida pela decisão da bancada empresarial de se retirar das plenárias de grupo, no segundo dia, e da plenária final, com o aval da Comissão Organizadora da Conferência, é outro exemplo de distorção, senão da concepção, da prática do tripartismo.

A afirmação dos autores de que a PNSST (BRASIL, 2011) foi "fruto de pressões dos profissionais e representantes da sociedade civil desde a década de 1990", e de que a instituição da PNSTT pelo Ministério da Saúde (BRASIL, 2012) estabelece a participação do SUS no contexto da PNSST, necessita de alguns reparos em relação ao processo de construção de cada política e da relação entre elas.
O primeiro documento de uma política nacional de saúde do trabalhador foi construído entre 19992000 por grupo de trabalho constituído pelo Ministério da Saúde. Foi apresentado e discutido em seminário público realizado na Câmara de Deputados no início de 2001 (NOBRE, 2011). O principal questionamento feito pelas representações sociais e institucionais presentes foi se havia vontade política para a implantação da proposta. Ficou demonstrado que não. Com a argumentação de que deveria ter um plano de aplicação de recursos financeiros, o que evidentemente era necessário, mas que não foi providenciado, o Ministério da Saúde engavetou a proposta. Somente em 2004, já no Governo Lula, a Coordenação de Saúde do Trabalhador do Ministério da Saúde retoma internamente o documento da PNST de 2001 e elabora nova proposta, que acaba sendo substituída pelo processo então em andamento no Geisat desde sua reativação em 2003.

A atual PNSST foi resultado do engavetamento da PNSST produzida pelo Geisat, lançada e colocada em consulta pública na $3^{a}$ CNST em 2005. Este processo foi interrompido e a política passou a ser elaborada por uma comissão tripartite intersetorial, composta por bancadas de governo, empresarial e de trabalhadores (centrais sindicais), criada em 2009, que resultou na PNSST publicada em 2011. Não era a primeira vez que se alterava o nome da política, nem a primeira em que se descartava a produção do Geisat.

Cabe perguntar por que criar uma comissão tripartite para produzir uma norma que somente dispõe sobre (algumas) atribuições institucionais já previstas em lei e na Constituição Federal? Bases legais que, aliás, nem são mencionadas no decreto. E as responsabilidades e atribuições dos empregadores e dos trabalhadores? Mais graves do que as inconsistências apontadas pelos autores destacam-se os seguintes aspectos: em relação à sua implementação, o que mesmo se pretende com a menção à "participação voluntária das organizações representativas de trabalhadores e empregadores"? Significa diminuir a responsabilidade dos empregadores em relação à manutenção de condições de trabalho seguras e saudáveis e de proteção da saúde dos trabalhadores? Significa não assumir o preceito constitucional do direito dos trabalhadores à participação em todas as etapas e instâncias de implementação das políticas públicas que lhe dizem respeito? E a atribuição à Comissão Tripartite de Saúde e Segurança no Trabalho (CTSST) de estabelecer os mecanismos de validação e de controle social da PNSST? O que pensavam os propositores desta política em relação aos mecanismos e às instâncias de participação e controle social das políticas existentes, especialmente considerando-se que a participação e o controle social, por 
exemplo, no âmbito do SUS, já são garantidos em outras bases pela Constituição Federal? Seria importante saber como tem sido a participação das representações dos trabalhadores nesse processo; quais as perspectivas e posições das centrais sindicais.

Independentemente do processo da PNSST, em 2008, gestores, técnicos e coordenadores estaduais de ST, reunidos em Brasília, deliberam pela retomada da elaboração da política de ST no âmbito do SUS, para o qual se constitui grupo de trabalho com representações estaduais, sob coordenação da área técnica do Ministério da Saúde. Ao longo de 2009, ocorrem reuniões do GT e oficinas de trabalho com a participação de outros atores. Em maio de 2010, o GT apresenta a primeira versão da política, a qual é apresentada em algumas instâncias de gestão e controle social, a exemplo da Comissão Intersetorial de Saúde do Trabalhador do Conselho Nacional de Saúde (CIST/CNS), no 4o Encontro Nacional da Renast (30 junho a 1ำ julho), no Conselho Nacional de Saúde (julho 2010), no III Encontro das CIST (dezembro 2010). Após, passa por discussão no Colegiado da Secretaria de Vigilância em Saúde; vai para consulta pública (30 dias); recebe mais sugestões de conselhos de saúde, estaduais e municipais e de outros atores sociais; passa por discussão e pactuação nas instâncias e esferas de gestão do SUS - Conselho Nacional de Secretários Estaduais de Saúde (CONASS), Conselho Nacional de Secretários Municipais de Saúde (CONASEMS), Comissão Intergestores Tripartite (CIT); retorna para discussão e aprovação no Conselho Nacional de Saúde; passa por revisão jurídica da Procuradoria do MS; nesse processo, a proposta incorpora sugestões e vai sendo aprimorada, resultando na atual PNSTT, Portaria MS/GM no 1.823, publicada em 23 de agosto de 2012 (BRASIL, 2012).

Desse modo, considero que a PNSTT, mesmo tendo sido aprovada e publicada em 2012, após a PNSST, não pode com ela se confundir. Os princípios, os objetos, os processos de construção, as participações sociais, as pactuações foram bastante diversas. Poderão e deverão se articular, complementar-se e ser compartilhadas? É claro que sim. Desde que tenhamos claras suas histórias, seus propósitos e seus alcances.

Rememoro todos esses fatos por considerar que complementam a análise dos autores acerca das contradições e dos paradoxos que vivenciamos e das posições do Estado na condução "da política real, que conjuga interesses do Estado e do capital", pautada pelos princípios do liberalismo, que é o lastro para a manutenção da fragmentação das ações institucionais, para o esvaziamento dos serviços e das políticas públicas, na perspectiva da anulação do Estado provedor" (COSTA; LACAZ; JACKSON FILHO; VILELA, 2013, p. 16). Como os processos trazem consigo as contradições, e nelas as oportunidades, também trago esses fatos na esperança de que, talvez, se tivermos capacidade, lucidez e coragem, ainda possamos refletir sobre e aprender com as rupturas e os conflitos de modo a resgatar novas possibilidades de construção compartilhada. Nesse sentido, a PNSTT aponta algumas potencialidades e muitos desafios.

Os autores apontam alguns nós críticos e fragilidades da Rede de Atenção à Saúde do Trabalhador (Renast) que são reais. Frente a eles, questionam se é possível garantir as ações de vigilância em ST no SUS. Penso ser necessário aprofundar a análise sobre esses aspectos, bem como clarear as proposições da PNSTT, entendendo o momento atual de amadurecimento das discussões sobre a saúde do trabalhador no SUS.

O diagnóstico apontado pelos autores, que consta dos documentos ministeriais, relatórios de gestão, em pesquisas, nos encontros regionais e nacionais, dá conta de diversos nós críticos, que vão de dificuldades de gestão da política, das insuficiências do planejamento, de insuficientes e ou inadequados indicadores de monitoramento e avaliação, até as fragilidades técnicas, na assistência e na vigilância, na produção e análise de informações. Há fragilidade e insuficiência nos modelos de gestão e nos modelos de atenção propostos; a descentralização ainda não é uma realidade; criaram-se centros de gestão municipal para dar conta de ações em abrangência regional; nem metade das regiões do país tem um centro de referência especializada como sua retaguarda técnica; a população trabalhadora, as atividades produtivas, as necessidades, os problemas de ST e as ações para enfrentá-los praticamente não existem na maior parte dos planos de saúde país afora; os perfis, de qualificação e composição, das equipes técnicas e gerenciais são insuficientes e inadequados; os vínculos frequentemente são precários; as concepções sobre ST e especialmente sobre Vigilância em Saúde do Trabalhador (Visat) frequentemente são distorcidas; há inúmeras fragilidades, carências, insuficiências; a estratégia adotada de rede de unidades sentinela esgotou-se frente à necessidade de incorporar as ações de ST em toda a rede SUS e de ter a atenção básica como ordenadora do sistema e a vigilância em saúde como eixo estratégico central (BAHIA, 2010; LACAZ; MACHADO; PORTO, 2002; DIAS; HOEFEL, 2005; SANTANA; SILVA, 2009; GONÇALVES; DIAS, 2009; NOBRE; 2011; CORREA; PINHEIRO; MERLO, 2012).

Sobre a Renast e o papel dos Centros de Referência em Saúde do Trabalhador (Cerests), considero que a PNSTT aponta para uma importante revisão e reconfiguração de sua arquitetura, funções e 
papéis. Ao explicitar a necessidade de implementação de ações de saúde do trabalhador em todos os níveis de atenção do SUS em uma concepção de rede, cuja ordenadora deve ser a Atenção Primária, a ST amplia suas possibilidades. A Renast não está mais restrita à atuação dos centros de referência. Entretanto, o papel dos Cerest não somente continua sendo fundamental, como retaguarda técnica especializada para toda a rede, como assume uma concepção de complexidade crescente, compartilhando conhecimentos e práticas com os demais setores ou pontos de atenção, especialmente com as vigilâncias em saúde, presentes em cada município do país. Desse modo, a PNSTT alinha-se internamente com o conjunto de políticas de saúde no âmbito do SUS, considerando a transversalidade das ações de saúde do trabalhador e o trabalho como um dos determinantes do processo saúde-doença.

Do princípio da universalidade decorre que são sujeitos da PNSTT todos os trabalhadores, homens e mulheres, independentemente de sua localização, urbana ou rural, de sua forma de inserção no mercado de trabalho, formal ou informal, de seu vínculo empregatício, público ou privado, assalariado, autônomo, avulso, temporário, cooperativados, aprendiz, estagiário, doméstico, aposentado ou desempregado. Com exceção de parcelas de trabalhadores formais, os demais são praticamente invisíveis para os serviços de saúde em suas necessidades e especificidades enquanto trabalhadores. É possível afirmar que há barreiras de acesso em relação a várias ações e instâncias do sistema (MIQUILIN; CORRÊA FILHO, 2011). Mesmo os trabalhadores celetistas frequentemente buscam o SUS somente como meio para garantir seus direitos previdenciários; em especial aqueles que dispõem de planos e seguros privados coletivos de saúde.

Que implicações decorrem disso? Identificar a condição de trabalhador/a e as situações de trabalho em todos os pontos da rede e em todos os níveis do sistema, desde a identificação do perfil da população trabalhadora e das atividades produtivas no território, das suas demandas e necessidades de saúde, até o planejamento de ações de atenção e vigilância. A começar pela atenção básica ou atenção primária em saúde, até a atenção de maior densidade tecnológica. Implica pensar os territórios e sua dinâmica produtiva, com suas atividades e cadeias produtivas, com trabalhadores vivendo, residindo, trabalhando e circulando nesses territórios. Essa é uma grande potencialidade do SUS. Dar visibilidade à população trabalhadora, às atividades produtivas, aos fatos e acontecimentos nos territórios, aos impactos à saúde, identificar necessidades e problemas na ótica da intervenção em saúde coletiva, mobilizando os refe- renciais, os instrumentos e as práticas, articulando e construindo a integralidade da atenção.

Considerar o trabalho como um dos determinantes do processo saúde-doença implica: produzir informações para o conjunto dos trabalhadores e não somente para a população coberta pela Previdência Social; viabilizar sua inclusão nas análises de situação de saúde; identificar toda a população trabalhadora, suas necessidades e demandas; incluir ações de ST nos planos de saúde; planejar, executar e avaliar essas ações. Com frequência as atividades produtivas impactam profundamente as dinâmicas populacionais, ambientais e do desenvolvimento nos territórios. É importante que na declaração de seu propósito, a PNSTT tenha feito menção aos modelos de desenvolvimento, além dos processos produtivos, que estão na origem de parte do perfil de morbimortalidade dos trabalhadores. Isso, somado à inclusão da precaução como um de seus princípios, atualiza e reforça a potencial contribuição do SUS na discussão sobre desenvolvimento, crescimento econômico e sustentabilidade socioambiental, tão necessária na conjuntura atual. Tomando emprestada a proposição de Fadel, trata-se de viabilizar a "vigilância do desenvolvimento" (VASCONCELOS, 2007), resgatando e fortalecendo as iniciativas e as experiências que adotam os princípios da sustentabilidade socioambiental, da justiça ambiental, da diminuição das inequidades, inclusão social, participação e controle social (RIGOTTO, 2005; PORTO, 2005).

Na avaliação da PNSST, os autores consideraram tímida a proposição de fortalecimento das ações de vigilância pelo MS e SUS. Já apresentei minhas considerações a respeito da PNSST. Entretanto, se olharmos o conceito de Visat já construído no âmbito do SUS e o que está proposto na PNSTT, diria que esta não é exatamente uma posição "tímida". Ao contrário, se conseguirmos efetivar boa parte do que consta na PNSTT, será um avanço e tanto. O fortalecimento da Visat e a integração com os demais componentes da Vigilância em Saúde, primeiro objetivo explicitado na PNSTT, pressupõem uma série de ações, dentre elas: 1) realização da análise da situação de saúde dos trabalhadores; intervenção nos processos e nos ambientes de trabalho; 2) produção de tecnologias de intervenção, de avaliação e de monitoramento das ações de Visat; 3) produção de protocolos, de normas técnicas e regulamentares; e 4) participação dos trabalhadores e suas organizações. Se a esse elenco acrescermos as ações que compõem o segundo objetivo - promover a saúde e ambientes e processos de trabalhos saudáveis, veremos que o desafio é, na verdade, imenso.

A Visat é sem dúvida das tarefas mais ricas e mais complexas a serem absorvidas pelo SUS (BRA- 
SIL, 1998). Também a mais "estranha" ao sistema, no sentido de que são capacidades, habilidades, competências, conhecimentos e práticas não aprendidos pelos profissionais em sua formação acadêmica. Necessitam ser criados, construídos e vivenciados. É o que ocorre, por exemplo, quando nos deparamos com as dificuldades de intervenção nos ambientes de trabalho, com a necessidade de operacionalização dos princípios e conceitos da vigilância em saúde do trabalhador nos SUS. Os ambientes de trabalho são frequentemente vistos como locais em que se desenvolvem processos tecnológicos, desprovidos de relações sociais, de interesses e conflitos, passíveis de serem controlados unicamente por decisões técnico-operacionais, por aplicação e cumprimento de procedimentos (NOBRE; GALVÃO; CARDIM; MENDES, 2010).

O desenvolvimento de práticas cartoriais e rituais burocráticas não é prerrogativa dos setores de vigilância sanitária do SUS. Infelizmente, esse tipo de concepção ainda é bastante comum às nossas instituições, sejam da Saúde, da Previdência Social ou do Trabalho, para ficar nas diretamente discutidas neste debate. Ainda não é predominante o entendimento da ação de Visat como prática pedagógica, sistemática, intersetorial e que incorpora a participação, os saberes e a subjetividade dos trabalhadores, produtora de conhecimentos e práticas inter e transdisciplinares. Sabemos que as ricas experiências de Visat de alguns centros de referência somente poderão ser ampliadas para outros municípios e estados mediante grande investimento e comprometimento de técnicos e gestores, bem como mediante esforços de integração intra e interinstitucional e articulação das ações em redes solidárias de compartilhamento de práticas e saberes (NOBRE; GALVÃO; CARDIM; MENDES, 2010; CORRÊA; PINHEIRO; MERLO, 2012).

O entendimento da responsabilidade sanitária de gestores e profissionais de saúde de proteger a saúde dos trabalhadores em seus locais de trabalho, tal como posto na PNSTT, auxilia-nos. Assumir o princípio ético-político da ação sanitária em ST compreende o entendimento de que o objetivo e a justificativa da intervenção é a melhoria das condições de trabalho e de saúde dos trabalhadores. Para isso, é fundamental avançar no equacionamento de outro grande desafio, também apontado pelos autores, que é poder contar com profissionais qualificados, comprometidos com a política de saúde e com responsabilidade sanitária; que façam a diferença e aliem capacidade técnica e concepção política e ideológica na luta por melhores condições de saúde e trabalho, compromissado com a construção do SUS e com os trabalhadores. As ações propostas para o desenvolvimento e capacitação de recursos humanos apontadas na PNSTT são, a bem da verdade, necessárias em todas as instâncias do SUS. Várias delas são desafios também para os demais setores das políticas públicas de interesse à ST e poderiam ser compartilhadas mediante estratégias específicas.

Entretanto, para melhor compreensão do tamanho dos desafios que se nos apresentam e de modo a completar as possibilidades de respostas aos questionamentos dos autores, cabe contextualizar o seguinte. Os maiores entraves, limites e desafios da ST no SUS são os próprios limites, nós críticos e desafios de todo o SUS. As considerações teórico-conceituais de alguns estudiosos (PAIM, 2009; SANTOS, 2009; FLEURY, 2009) acerca das políticas sociais, das políticas e práticas de saúde, do caráter do Estado brasileiro e das contradições da sociedade contemporânea, em suas análises sobre a reforma sanitária brasileira, ajudam-nos na compreensão dos nós críticos do SUS. Como um processo de reforma social concebida em um momento de crise de hegemonia e na defesa da democratização do Estado e da sociedade, vai perdendo força e vigor, ao tempo em que vai se institucionalizando. Um Estado que desenvolve políticas sociais, tanto em atenção a necessidades sociais quanto em atendimento às demandas de reprodução do capital.

Alguns nós críticos são praticamente unanimidade também entre técnicos e gestores do SUS. Um dos mais importantes, o subfinanciamento do setor, atinge todas as áreas do SUS e explicita a contradição de uma política que, para garantir direito à saúde, amplia o acesso da população aos serviços de saúde ao mesmo tempo em que permite e fomenta o crescimento exponencial dos investimentos no setor privado de saúde. Desde a retirada da contribuição previdenciária para a saúde, em 1993; a não aplicação da CPMF na saúde e depois sua extinção; a pressão de setores governamentais federais para não regulamentar a Emenda Constitucional no 29 e, com ela, impedir a aplicação do percentual sobre a arrecadação da União para o financiamento do sistema; até as diversas modalidades de comprometimento do orçamento público federal, a exemplo do financiamento indireto das empresas privadas de planos e seguros de saúde pela dedução do Imposto de Renda, do cofinanciamento de planos privados dos servidores públicos (incluindo as estatais), do não ressarcimento ao SUS pelas empresas de planos e seguros pelos atendimentos feitos a seus afiliados, isenções tributárias e outras (SANTOS, 2009).

Afora isso, os insuficientes recursos são desigualmente distribuídos, sendo aplicados majoritariamente em serviços hospitalares e procedimentos assistenciais de média e alta complexidade, pouco restando para a atenção básica ou saúde da família ou para 
ações de promoção da saúde e vigilância em saúde. É assim na atenção de uma forma geral e é assim na ST. A PNSTT deixa claro que o financiamento das ações de saúde do trabalhador deve ser responsabilidade dos três entes da federação, União, estados e municípios, e que deve ser compartilhado entre os diversos blocos de financiamento hoje existentes no SUS, além de ser possível acionar outras fontes de financiamento. Será necessária muita pressão social e gestão para que o que está escrito saia do papel e apareça na vida real, na política real.

É importante ressaltar que o subfinanciamento do SUS e, especialmente, as opções que favorecem a manutenção e até crescimento dos planos e seguros de saúde privados impactam de várias formas no potencial de êxito ou enfraquecimento da PNSTT. Além dos limites relativos ao modelo de atenção, individual, curativo, que não valoriza a promoção, prevenção e medidas básicas de vigilância em saúde, a exemplo da notificação de casos de acidentes e doenças relacionadas ao trabalho, há pouca margem para o exercício do controle social e regulação do Estado. De fato, observa-se uma inversão na agenda política dos trabalhadores e suas representações, ao inserir os planos e seguros privados como objeto de reivindicação em seus acordos coletivos, restando, quase sempre, à defesa do SUS e de condições dignas de trabalho um locus marginal. É um impacto quase invisível, mas altamente potente, seja em seus resultados concretos, seja nas suas dimensões simbólicas, ideológicas e culturais.

Outra ordem de desafios consiste em como pensar e praticar modelos de gestão que superem:

\begin{abstract}
a pesada herança da formação do Estado brasileiro, unitário, avesso à diversidade regional e local, cartorial, patrimonialista, burocratizado e clientelista, com a administração pública direta e indireta impregnadas com todas as vertentes particularistas e corporativistas. (SANTOS, 2009, p. 21)
\end{abstract}

Atualmente, há uma importante discussão a respeito da gestão participativa, solidária e compartilhada entre os entes federativos, com responsabilidade sanitária, com valorização dos sujeitos, e das formas de participação social que incluem e, ao mesmo tempo, extrapolam, as instâncias constituídas de controle social. A par disso, ressaltam-se as proposições sobre modelos de atenção pautados na lógica de redes, menos hierarquizadas e mais solidárias, com recursos e estratégias de apoio, de compartilhamento de saberes, experiências e práticas, tendo como base e ordenadora do sistema a atenção primária em saúde e como diretrizes estratégicas a promoção da saúde e a vigilância em saúde (SANTOS, 2009; PAIM, 2009).

Todos esses aspectos, que trazem novos ares aos processos concretos de construção da política de saúde nos territórios, nos municípios e estados, es- tão pontuados nos objetivos, nas diretrizes, nas estratégias e nas responsabilidades institucionais da PNSTT. O papel da Atenção Primária à Saúde na ST já tem um corpo de reflexões e propostas concretas sendo experimentadas, com resultados positivos e surpreendentes (GONÇALVES; DIAS, 2009; SANTOS; LACAZ, 2012; DIAS; SILVA, 2013).

Sobre a participação e o protagonismo dos trabalhadores e suas representações nessas e noutras políticas, especialmente em tempos de crise e aprofundamento da globalização, é preciso lembrar o que uma vez aprendemos com o movimento operário italiano: "saúde não se vende”, "a defesa da saúde não se delega” (ODDONE, 1986). Este princípio, caro à ST, pois não há saúde dos/as trabalhadores/as sem os/as trabalhadores/as, sujeitos de sua história, deve ser tomado em sua radicalidade. As centrais sindicais, os sindicatos de trabalhadores e de suas entidades apoiadoras, como Dieese e Diesat, cumprem papel político e social importantíssimo, tanto na defesa de seus próprios interesses, quanto na perspectiva da inclusão e ampliação da participação de parcelas de trabalhadores e movimentos sociais historicamente excluídos.

As reflexões de Sônia Fleury sobre o processo e os rumos da reforma sanitária brasileira parecem bastante adequadas e pertinentes ao entendimento da história da ST no SUS e ao desafio atual de repolitização da área:

O paradoxo da reforma sanitária brasileira é que seu
êxito, ainda que em condições adversas e parciais,
terminou por, ao transformá-la em política públi-
ca, reduzir a capacidade de ruptura, de inovação e
construção de uma nova correlação de forças desde
a sociedade civil organizada. Em outras palavras, o
instituído se impôs ao instituinte, reduzindo o ca-
ráter libertário e transformador da reforma. A cons-
tatação de que a iniquidade estrutural da sociedade
brasileira atravessa hoje o Sistema Único de Saúde
é a possibilidade de retomar o combate pelas ideias
igualitárias que orientaram a construção deste pro-
jeto. Para tanto, resta a questão da construção per-
manente do sujeito, aquele que poderá transformar
novamente o instituído em instituinte, para de novo
institucionalizar-se. (FLEURY, 2009, p. 751)

Proponho que uma forma de responder aos desafios postos pelos autores seja recuperar e atualizar a força instituinte da Saúde do Trabalhador, pensar que novas mudanças, reconfigurações institucionais e práticas reflexivas são necessárias para efetivar o que acabamos de construir, pois uma política precisa ser viva, precisa fazer parte dos desejos, das vontades, das necessidades, das perspectivas e objetivos dos sujeitos.

Por tudo isso, todas as proposições da PNSTT são muito bem-vindas. Os desafios são inúmeros, mas também já há experiência acumulada. Não fosse assim, não construiríamos o novo, não haveria alter- 
nativas. Essas questões devem ser pensadas juntamente com todas as outras necessidades e gargalos do SUS. Certamente não se esgotaram as respostas; boas perguntas suscitam muitas vezes outras perguntas, apontam para outros caminhos. O desafio está posto para todos e todas que construímos e compartilhamos esta história. Aproveitemos, pois,

\section{Referências}

ABRAMO, L. Trabalho Decente: o itinerário de uma proposta. Bahia Análise e Dados, Salvador, v. 20, n. 2/3, p. 151-171, jul-set 2010.

BAHIA (Estado). Secretaria da Saúde. Superintendência de Vigilância e Proteção da Saúde. Diretoria de Vigilância e Atenção à Saúde do Trabalhador. Plano estratégico de saúde do trabalhador no Estado da Bahia - PLANEST - 2010. Salvador: SESAB/SUVISA/DIVAST, 2010. (mimeo).

. Secretaria do Trabalho, Emprego, Renda e Esporte. Programa Bahia do trabalho decente. Salvador: SETRE, 2011.

BRASIL. Ministério da Saúde. Conselho Nacional de Saúde. $2^{\text {a }}$ Conferência Nacional de Saúde do Trabalhador: construindo uma política de saúde do trabalhador. Relatório final. Brasília: Ministério da Saúde, 1994.

. Portaria MS/GM n⿳ำ 3.120 , de $1^{\circ}$ de julho de 1998. Aprova a Instrução Normativa de Vigilância em Saúde do Trabalhador no SUS. Diário Oficial [da] República Federativa do Brasil, Brasília, 02 julho 1998. Disponível em: <http://www.cerest.piracicaba.sp.gov. br/site/images/3120_-_98.pdf $>$. Acesso em: 09 dez. 2013.

. Ministério da Saúde. Ministério da Previdência Social. Ministério do Trabalho e Emprego. Portaria Interministerial MPS/MS/MTE n⿳o 800, de 3 de maio de 2005. Publica o texto base da minuta de Política Nacional de Segurança e Saúde do Trabalhador. Diário Oficial [da] República Federativa do Brasil, Brasília, 5 maio 2005. Disponível em: <http://www.previdenciasocial.gov.br/arquivos/ office/3_081014-105449-562.pdf >. Acesso em: 15 nov. 2010.

. Portaria $\mathrm{n}^{\mathrm{o}}$ 1.823, de 23 de agosto de 2012. Institui a Política Nacional de Saúde do Trabalhador e da Trabalhadora. Diário Oficial [da] República Federativa do Brasil, noำ 165, Seção I, p. 46-51, 24 ago. 2012. Disponível em: <http://bvsms.saude.gov.br/ bvs/saudelegis/gm/2012/prt1823_23_08_2012.html>. Acesso em: 09 dez. 2013.

CORREA, M. J. M.; PINHEIRO, T. M. M.; MERLO, A. R. C. (Org.). Vigilância em saúde do trabalhador no Sistema Único de Saúde. Belo Horizonte: Coopmed, 2012. de forma criativa, construtiva e solidária a oportunidade já sinalizada da próxima $4^{-}$Conferência Nacional de Saúde do Trabalhador.

Agradeço à RBSO por semear este debate; a Danilo, Lacaz, Marçal e Rodolfo pelas reflexões, dúvidas e parcerias.
COSTA, D.; LACAZ, F. A. C.; JAKSON FILHO, J. M.; VILELA, R. A. G. Saúde do Trabalhador no SUS: desafios para uma política pública. Revista Brasileira de Saúde Ocupacional, São Paulo, v. 38, n. 127, 11-30, 2013.

DIAS, E. C.; HOEFEL, M. G. O desafio de implementar as ações de saúde do trabalhador no SUS: a estratégia da Renast. Ciência \& Saúde Coletiva, Rio de Janeiro, v. 10, n. 4, p. 817-828, 2005.

DIAS, E. C.; SILVA, T. L. (Org.). Saúde do Trabalhador na Atenção Primária à Saúde: possibilidades, desafios e perspectivas. Belo Horizonte: Coopmed, 2013.

FLEURY, S. Reforma sanitária brasileira: dilemas entre o instituinte e o instituído. Ciência \& Saúde Coletiva, Rio de Janeiro, v. 14, n. 3, p. 743-752, 2009.

GONÇALVES, K. R.; DIAS, E. C. Direito à Saúde \& Saúde do Trabalhador: aproximações para entender e agir. In: OLIVEIRA, M. H. B.; VASCONCELLOS, L. C. F. (Org.). Direito \& Saúde: um campo em construção. Rio de Janeiro: Ediouro, 2009.

LACAZ, F. A. C.; MACHADO, J. M. H.; PORTO, M. F. S. Estudo da situação e tendências da vigilância em saúde do trabalhador no Brasil. Projeto - relatório de resultados do questionário. [S.I.]: OPAS; Ministério da Saúde; Abrasco. 2002.

MIQUILIN, I. O. C.; CORRÊA FILHO, H. R. Propostas de inclusão dos trabalhadores informais e desempregados nas políticas públicas brasileiras: breve análise a partir das Conferências Nacionais de Saúde do Trabalhador. Saúde em Debate, Rio de Janeiro, v. 35, n. 90, p. 426-436, jul./set. 2011.

NOBRE, L.C.C. Relações entre produção, trabalho, ambiente e saúde: a contribuição do Sistema Único de Saúde para a conquista do Trabalho Decente. Bahia Análise e Dados, Salvador, v. 20, n. 2/3:339-348; jul-set 2010.

. A Política de Saúde do Trabalhador no Brasil e na Bahia. In: NOBRE, L.; PENA, G. L. P.; BAPTISTA, R. (Org.). A Saúde do Trabalhador na Bahia - História, conquistas e desafios. Salvador: Edufba; Sesab; Cesat, 2011. p. 23-92.

NOBRE, L. C. C.; GALVÃO, A. M. F.; CARDIM, A.; MENDES, T. T. Vigilância em Saúde do Trabalhador no Sistema Único de Saúde: práticas e desafios. In: NOBRE, L.; PENA, G. L. P.; BAPTISTA, R. (Org.) A 
Saúde do Trabalhador na Bahia - História, conquistas e desafios. Salvador: Edufba; Sesab; Cesat, 2011. p. 275-314.

ODDONE, I et al. Ambiente de Trabalho - a luta dos trabalhadores pela saúde. São Paulo: Hucitec, 1986.

PAIM, J. S. Uma análise sobre o processo de Reforma Sanitária brasileira. Saúde em Debate, Rio de Janeiro, v. 33, n. 81, p. 27-37, jan./abr. 2009.

PORTO, M. F. Saúde do trabalhador e o desafio ambiental: contribuições do enfoque ecossocial, da ecologia política e do movimento pela justiça ambiental. Ciência \& Saúde Coletiva, Rio de Janeiro, v. 10, n. 4, p. 829-839, 2005.

RIGOTTO, R. M. Saúde dos trabalhadores e ambiente: por um desenvolvimento sustentável? Desenvolvimento Sustentável, o que é? In: BRASIL. Ministério da Saúde. $3^{\underline{a}}$ Conferência Nacional de Saúde do Trabalhador "Trabalhar sim, adoecer não!": coletânea de textos. Brasília: Ministério da Saúde, 2005. p. 156-161.
SANTANA V.; SILVA, J. M. Os 20 anos de saúde do trabalhador no Sistema Único de Saúde do Brasil: limites, avanços e desafios. In: Saúde Brasil 2008: 20 anos do Sistema Único de Saúde (SUS) no Brasil. [S.I.]: Secretaria de Vigilância em Saúde, Ministério da Saúde, 2009.

SANTOS, N. R. A Reforma Sanitária e o Sistema Único de Saúde: tendências e desafios após 20 anos. Saúde em Debate, Rio de Janeiro, v. 33, n. 81, p. 13-26, jan./ abr. 2009.

SANTOS, A. P. L.; LACAZ, F. A. C. Apoio Matricial em Saúde do Trabalhador: tecendo redes na Atenção Básica do SUS, o caso de Amparo/SP. Ciência \& Saúde Coletiva, Rio de Janeiro, v. 17, n. 5, p. 1143-1150, 2012.

VASCONCELLOS, L. C. F. Saúde, trabalho e desenvolvimento sustentável: apontamentos para uma política de Estado. 2007. 421 f. Tese (doutorado em Saúde Pública)-Escola Nacional de Saúde Pública Sérgio Arouca, Fundação Oswaldo Cruz, Rio de Janeiro, 2007.

Recebido: 17/09/2013

Aprovado: 25/11/2013 